\title{
An Analysis of English language reading skills of Students: A Case Study of Faculty of Biological Sciences of University of Malakand,Khyber Pukhtunkhwa, Pakistan.
}

\author{
Sami Ul Haq \\ Tipu Shaheed School \& Degree College, Kabal Swat - Pakistan
}

Abstract: This study was conducted to examine the proficiency level of English language reading skill of science students. It focused those components of the curriculum that play a role in its improvement and development. The reading skills and habits of students were also examined through data collected from one hundred and twenty students of Faculty of Biological sciences of the University of Malakand, Khyber Pukhtunkhwa, Pakistan, through a questionnaire. The data were analysed using simple percentages method.The findings of the study revealed that the students had improved reading skill up after taking admission in the university. The study concludes that the inclusion of English language courses as compulsory part of the curriculum had a positive contribution. It also concludes that employing effective teaching strategies and giving more space to the language course was of great help in nurturing necessary skills. The study also concludes that English language input is necessary and played pivotal role in the academic journey of the students in dealing with other subjects in a teaching situation where the medium of instruction is English.

Keywords: English Language, Reading, Science curriculum

\section{INTRODUCTION}

Language educators have long used the concepts of four basic language skills: Listening, Speaking, Reading \& Writing. These four language skills are sometimes called the "macro-skills". This is in contrast to the "micro-skills", which are things like grammar, vocabulary, pronunciation and spelling. The four basic skills are related to each other by two parameters: the mode of communication: oral or written and the direction of communication: receiving or producing the message (Aydoğan\&Akbarov, 2014). The four basic skills of English language have played a vital role in the progress, development and job market of fresh graduates. Proper education in English is, in fact, necessary for national development. Yet, making it compulsory for the common person to learn English and arranging for its effective teaching at higher levels, for the study of science and technology, and for communication with the outside world are two different things (Khalid \& khan, 2006). 
Roberts and Wilson (2006) have viewed that "Reading attitude is an integral part of the development and use of lifelong reading skills. Positive attitude toward learning is one of the most important psychological concepts in education. Tran (2006) has emphasized that "Free voluntary reading has supported not only vocabulary development, but also spelling, grammar, and writing development".

The mastery in basic skills of English language especially reading and writing are the need and requirement of science graduates. They can compile and write various reports, research papers and field descriptions. Reading is a multifaceted process involving word recognition, comprehension, fluency, and motivation. Readers integrate these facets to make meaning from print. Reading is an important gateway to personal development, and to social, economic and civic life (Holden, 2004).

\section{Significance of the study}

This research study is highly accountable for the following factors:

1. This research study provides a platform for future researchers to know about the research in the field of English language learning with special reference to reading skills.

2. This research work is highly valuable for students to analyze thir English language skills in science curriculum.

\section{Research Objectives}

1. To Examine the English language reading skills of degree level science students during their education.

2. To judge the learning level of science students in the field of English language learning.

3. To know about reading proficiency of students of faculty of biological science at University of Malakand before and during their educational career.

\section{RESEARCH METHOD}

Quantitative method as a research technique was used to gather quantitative data. This is a systematic process in which numerical data are collected, controlled and measured to address the accumulation of facts and results (Nunan, 2001). Questionnaire was used as a tool for data collection in different departments such as Department of Zoology, Department of Botany and Department of Biotechnology of Biological sciences at BS level in University of Malakand. The total strength of students in these three departments of is four hundred and eighty (480), out of these, only one hundred and twenty (120) students for the current study on the basis of forty (40) students from each department were selected. These forty students from each department are further divided i.e. ten (10) students from each semester. In each class/semester ten (10) students are selected randomly on the basis of their attendance in attendance register. The students, who have odd attendance numbers in the register, are selected for this study. According to this criterion, ten (10) students from each 
class/semester, forty (40) students from each department on semester basis and finally one hundred and twenty (120) students from faculty of Biological sciences were selected. Firstly, students were selected on the basis of above mentioned criteria from the faculty of Biological sciences. Meetings were conducted with concerned head of departments and teachers. Then according to time table and schedules we jointly agreed on a workable plan. In this way, places were identified in each department such as, class or break time (scheduled) for filling the questionnaires. We also managed to inform and instruct the students about our methodology, purpose of research, the terms and conditions \& the meaning and nature of questions at the time of filling questionnaires. Thereafter, a time of average one hour was given for performing the task. Later on, we would collect the filled questionnaires with due acknowledgment of the respondents' cooperation in the research study. The data were arranged into tables that was then analysed on the basis of percentage in each category. It was not uniform and for instance the second question was divided into four tables according to semester wise categorization due to nature of the question, and rest of the tables presented question-wise data.

\section{DATA ANALYSIS}

To analyze the data, the students from these three departments were placed in groups according to their semester wise categorization i.e. thirty (30) students of $2^{\text {nd }}$ semester from the three departments placed in one group and so on.

\section{Knowledge of Reading Skill before University Education}

To start with, data regarding basic knowledge and understanding of reading and writing skills was collected that is presented in the following tables with relevant discussion.

Table 1. Evaluating Student's Previous Knowledge

\begin{tabular}{ccccc}
\hline & Trainee & In-between & Progressive & Total \\
\hline Reading & $09(7.5 \%)$ & $71(59.16 \%)$ & $40(33.33 \%)$ & 120
\end{tabular}

The table demonstrates that majority of the respondents i.e. 71 out of 120 $(59.16 \%)$ in reading section of the total sample lie in the "in-between" category. The figure also indicates that these students had got marks up to $60 \%$ in the subject of English at intermediate level i.e. in their qualifying exam for admission at BS level. It further shows that these students had basic knowledge about comprehension, basic grammar, basic sentence structure and capitalization etc. of English language reading. These students are placed in the average category because their result at HSSC (intermediate) shows their competency of English language at that level.

The second group of the respondents is i.e. 40 out of $120(33.33 \%)$ in reading section out of the total sample were in the "progressive" category. They were talented and had brilliantly performed at intermediate level. Their marks at intermediate level (The criterion for marks in HSSC was already explained in the questionnaire) show their mastery of English language reading, and writing. 
The last and tiny group of respondents i.e. 9 out of $120(7.50 \%)$ in reading section of the total sample were included in the "trainee" category. The students were weak at intermediate level. Their marks at intermediate level showed their poor performance and inability of English language reading.

\section{Knowledge about English Language Reading Skill after Spending Time in University}

The following table shows the data dealing with the knowledge about English language reading skill, according to your own perception, after spending time in university.

Table 2.1. Data about $2^{\text {nd }}$ semester

\begin{tabular}{ccccc}
\hline & Trainee & In-between & Progressive & Total \\
\hline Reading & $0(0 \%)$ & $9(30 \%)$ & $21(70 \%)$ & 30
\end{tabular}

The table 2.1. demonstrates that most of the students were in progressive category, 21 out of $30(70 \%)$ in reading category. The figure shows that after spending one semester in university, these students have gained proficiency up to some extent in English reading.

The second group of respondents i.e. 9 out of 30 (30\%) in reading section were placed in the "in-between" category. This group consisted of weak students in the class but they had improved up to some extent. The absence of students in trainee category also indicates that students had improved and gained knowledge up to some extent in English reading.

Table 2.2. Data about $4^{\text {th }}$ semester

\begin{tabular}{ccccc}
\hline & Trainee & In-between & Progressive & Total \\
\hline Reading & $0(0 \%)$ & $9(30 \%)$ & $21(70 \%)$ & 30
\end{tabular}

The table 2.2. demonstrates that most of the students were in progressive category i.e. 17 out of $30(56.66 \%)$ in reading section. The figure shows that after spending three semesters in university, these students had gained proficiency in English language reading and writing. In the table, the second group of respondents i.e. 08 out of $30(26.66 \%)$ in reading section of the total sample were in the "in-between" category. They were the group of average students in the class because they had improved up to some extent. The scarcity of students in the trainee category also showed improvement up to some extent in English reading.

Table 2.3. Data about $6^{\text {th }}$ semester

\begin{tabular}{ccccc}
\hline & Trainee & In-between & Progressive & Total \\
\hline Reading & $00(0 \%)$ & $11(36.66 \%)$ & $19(63.33 \%)$ & 30
\end{tabular}

The table demonstrates that most of the students were progressive i.e. 19 out of $30(63.33 \%)$ in reading. The figure shows that after spending five semesters in the university, these students had gained proficiency in English language reading. In the table, the second group of respondents i.e. 11 out of $30(36.66 \%)$ in reading section of the total sample were in the "in-between" category. They were 
weaker students in the class with improvement to some extent. They were however no student in the trainee category that showed that students had improved and gained knowledge of English reading.

Table 2.4. Data about $8^{\text {th }}$ semester

\begin{tabular}{ccccc}
\hline & Trainee & In-between & Progressive & Total \\
\hline Reading & $03(10 \%)$ & $10(33.33 \%)$ & $17(56.66 \%)$ & 30
\end{tabular}

The table demonstrated that most of the students were in progressive category i.e. 17 out of $30(56.66 \%)$ in reading category. The figure showed that after spending seven semesters in the university, the students had gained enough proficiency at that level.In the table, the other group of respondents is i.e. 10 out of $30(33.33 \%)$ in reading section of the total sample were in the "in-between" category. They were students with average performance in the class because their improvement was considerable to a lesser degree than those in the progressive category. Very few students were also rated in trainee category who had reduced level of proficiency in the skills under investigation.

\section{The Analysis of Improved Knowledge about English Language Especially Reading}

The following table showed the data dealing with the analysis of improved knowledge about english language reading.

Table 3.1. The Analysis of Improved Knowledge about English Language Reading

\begin{tabular}{ccccccc}
\hline & $\begin{array}{c}\text { Improved/Not- } \\
\text { improved }\end{array}$ & $\begin{array}{c}\text { Very } \\
\text { high }\end{array}$ & High & Medium & $\begin{array}{c}\text { Not at } \\
\text { all }\end{array}$ & Total \\
\hline Scanning & $116 / 04$ & 7 & 53 & 56 & 04 & 120 \\
Skimming & $109 / 11$ & $(5.83 \%)$ & $(44.16 \%)$ & $(46.66 \%)$ & $(3.33 \%)$ & 120 \\
Intensive & $114 / 06$ & $(5.83 \%)$ & $(40.83 \%)$ & $(44.16 \%)$ & $(9.16 \%)$ & 120 \\
reading & 11 & 46 & 57 & $06(5 \%)$ & 120 \\
$\begin{array}{c}\text { Extensive } \\
\text { reading }\end{array}$ & $108 / 12$ & $(9.16 \%)$ & $(38.33 \%)$ & $(47.5 \%)$ & & \\
& & $(8.33 \%)$ & $42(35 \%)$ & 56 & $12(10 \%)$ & 120 \\
\end{tabular}

The table demonstrated that majority of the respondents in "scanning section "were in medium category i.e. 56 out of $120(46.66 \%)$. It showed that most of the students had improved their scanning ability because of nature and need of study at university level.

\section{Scanning Section}

In "scanning section", 56 out of $120(46.66 \%)$ respondents were ranked in high category that indicated that most of them had improved their scanning ability of reading up to some extent because of nature and need of study at university level. There was however other respondents in "scanning section" who were placed in very high category i.e. 7 out of 120 (5.83\%). In every class there were certain students who were found hardworking and were classified as bright and intelligent students. These students had self-capabilities of learning and 
motivation. The semester system and university education had polished their skills.

A tiny section of the students i.e. 4 out of 120 (3.33) marked "not at all" category that pointed to lack of or scarcity of improvement chances in their skill development. They may also be categorized as the less attentive or non-serious respondents in the current research study.

\section{Skimming Section}

In "skimming section", majority of the students were in medium category i.e. 56 out of $120(46.66 \%)$. It showed that most of them had improved their scanning ability because of nature and need of study at university level. The next group of respondent in "skimming section" was placed in high category i.e. 53 out of $120(44.16 \%)$. It showed that most of the students had improved their scanning ability up to some extent because of nature and need of study at university level. The other respondents in "skimming section" were placed in very high category i.e. 7 out of $120(5.83 \%)$. As noted above, in every class there were certain hardworking students and were considered bright and intelligent students. These students had self-capabilities of learning and motivation. The semester system and university education had also polished their skills. Due to these factors they had achieved high proficiency in reading. The last category of respondents was placed in not at all category, which was 4 out $120(3.33 \%)$ because they were very weak in studies and there was less space of improvement for them. They can also be categorized as the non-serious section of the respondents in the current study.

\section{Intensive Reading Category}

The collected data revealed that majority of the respondents in "intensive reading category" were in medium category i.e. 57 out of 120 (47.5\%). It shows that most of the students have improved their scanning ability because of nature and need of study at university level. The next group of respondents in "intensive reading category" were placed in high category i.e. 38 out of $120(38.33 \%)$. It shows that most of the students have improved their scanning ability up to some extent because of nature and need of study at university level. The other respondents in "intensive reading category" were placed in very high category i.e. 11 out of $120(9.16 \%)$. In every class there were certain hardworking students and were considered bright and intelligent students. These students have selfcapabilities of learning and motivation. The semester system and university education had also polished their skills. Due to these factors, they have achieved high proficiency in reading. The last category of respondents was placed in not at all category, which was 6 out $120(5 \%)$ because this type of students were considered very weak in studies and there was less space of improvement for them. They can also be categorized as the non-serious section of the respondents in the current study.

\section{Extensive Reading Category}

The table demonstrates that majority of the respondents in "extensive reading category" were in medium category i.e. 56 out of 120 (46.66\%). It shows that most of the students have improved their scanning ability because of nature and need of study at university level. The next group of respondents in "extensive 
reading category" were placed in high category i.e 42 out of $120(35 \%)$. It shows that most of the students have improved their scanning ability up to some extent because of nature and need of study at university level.

The other respondents in "extensive reading category" were placed in very high category i.e. 10 out of $120(8.33 \%)$. In every class there were certain hardworking students and were considered bright and intelligent students. The semester system and university education had also polished their skills. Due to these factors, they have achieved high proficiency in reading. The last category of respondents was placed in not at all category, which was 12 out $120(10 \%)$ because they were very weak in studies and there was lesser degree of hope of improvement for them. Overall, the data shows that the students have improved and learned different reading techniques during the university education. There are different types of students present in the class who have different mental \& understanding levels. Hence, different types of students according to their learning and study needs have variously improved in different categories.

\section{The Components of Science Curriculum that Have Played a Role in Improving} English Language Skills

Table 4. The components of Science Curriculum that Have Played a Role in Improving English Language Skills

\begin{tabular}{cccccc}
\hline In reading & Very high & high & Medium & not at all & Total \\
\hline $\begin{array}{c}\text { Science } \\
\text { textbooks }\end{array}$ & $28(23.33 \%)$ & $58(48.33 \%)$ & $31(25.83 \%)$ & $03(2.5 \%)$ & 120 \\
$\begin{array}{c}\text { English } \\
\text { textbooks }\end{array}$ & $15(12.5 \%)$ & $52(43.33 \%)$ & $50(41.66 \%)$ & $03(2.5 \%)$ & 120
\end{tabular}

In the above table the field data regarding "The components of science curriculum that have played a role in improving English language skills" consist of two types of books i.e. science textbooks and English language textbooks. They are analyzed on the basis of four categories i.e. very high, high, medium and not at all.

\section{Reading Skill in Science Textbooks}

The table demonstrates that majority of the respondents i.e. 58 out of 120 $(48.33 \%)$ in "science textbooks section" of the total sample are in the "high" category. This figure shows that these students have improved their reading skills of English language by reading and studying science textbooks. The reason is that the corpus of the textbooks they study during their period of stay in the university include only 3 or 4 subjects of English language while the rest relate to science subjects. Hence, a large number of students have improved their reading ability in reading science textbooks.

The next category of the respondents are 28 out of $120(23.33 \%)$ in "science textbooks section" of the total sample in the "very high" category. This figure shows that these students have achieved high proficiency in reading. In every class there are certain students, which are hard-working and considered intelligent in the class. Hence, due to their skills, suitable textbooks \& teaching, they have achieved sufficiency in the art. The other group of the respondents is 31 out of $120(25.83 \%)$ in "science textbooks section" of the total sample in the 
"medium" category. This figure shows that these students have improved their reading skills up to some extent. These are considered average students of the class; hence they have achieved proficiency according to their ability and work. Then, the last group of the respondents is 03 out of $120(2.5 \%)$ in "science textbooks section" of the total sample in the "not at all" category. This figure shows that these students do not have improved their reading skills. These are considered less proficient in the art of reading.

\section{Reading Skill in English Textbooks}

The table demonstrates that majority of the respondents i.e. 52 out of 120 (43.33\%) in "English textbooks category" of the total sample are in the "high" category. This figure shows that these students have improved their reading skills of English language by reading concerned textbooks. The reason is that their course is consists of about 3 or 4 subjects of English language where they learn the basics of English language. They also benefit from other courses i.e. science textbooks where the language of these books is also English. The next category of the respondents i.e. 50 out of $120(41.66 \%)$ in "English textbooks category" of the total sample are in the "medium" category. This figure shows that these students have improved their reading skills up to some extent. These are considered average students of the class; hence they have achieved proficiency according to their ability and work. The other group of the respondents is 15 out of 120 $(12.5 \%)$ in "English textbooks category" of the total sample in the "very high" category. This figure shows that these students have achieved high proficiency in reading. In every class there are certain students, which are hard-working and considered intelligent in the class. Hence, due to their skills, suitable textbooks \& teaching, they have achieved greater proficiency. The last group of the respondents is 03 out of $120(2.5 \%)$ in "English textbooks category" of the total sample in the "not at all" category. This figure shows that these students do not have improved reading skills. These are considered weak and below average students of the class.

\section{Difficulties Faced by Students in Reading their Textbooks}

Table 5. Difficulties Faced by Students in Reading their Textbooks

\begin{tabular}{cccccc}
\hline & Very high & High & Medium & Not at all & Total \\
\hline $\begin{array}{c}\text { Difficulties } \\
\text { faced in the } \\
\begin{array}{c}\text { reading of } \\
\text { textbooks }\end{array}\end{array}$ & $16(13.33 \%)$ & $20(16.66 \%)$ & $60(50 \%)$ & $24(20 \%)$ & 120 \\
\hline
\end{tabular}

The table demonstrates that majority of the respondents in the category are in medium category i.e. 60 out of 120 (50\%). It shows that most of the students have faced a little bit difficulties in reading their textbooks. These students are hard-working and have background knowledge about different techniques of reading. The next group of respondents placed in "not at all category" is 24 out of $120(20 \%)$. In every class there are certain students that are hard-working and considered intelligent students. These students have self-capabilities of learning and motivation. They have not faced visible difficulties in reading their textbooks. The other respondents in the category are placed in "high category" i.e. 20 out of $120(16.66 \%)$. They have faced difficulties up to some extent in reading their 
textbooks because they are considered very weak in studies and they have low reading skills. The last group of respondents is placed in "very high category", which is 16 out $120(13.33 \%)$ because these students have faced a lot of difficulties in reading their textbooks. There are a lot of factors involved in it. These students have no background knowledge and are not interested in reading books and they mainly depend upon lectures \& notes.

\section{Difference between Scientific and Common English Language}

Table 6. Difficulties Faced by Students in Reading their Textbooks

\begin{tabular}{cccccc}
\hline & Very high & High & Medium & Not at all & Total \\
\hline $\begin{array}{c}\text { Difference } \\
\text { between }\end{array}$ & & & & & \\
$\begin{array}{c}\text { scientific and } \\
\text { common }\end{array}$ & $18(15 \%)$ & $50(41.66 \%)$ & $40(33.33 \%)$ & $12(10 \%)$ & 120 \\
$\begin{array}{c}\text { English } \\
\text { language }\end{array}$ & & & & & \\
\hline
\end{tabular}

The table demonstrates that most of the respondents in the category are in "high category" i.e. 50 out of $120(41.66 \%)$. In their view, there is very high difference between scientific and common English language. The next group of respondents in the category is placed in "medium category" i.e. 40 out of 120 $(33.33 \%)$. In the view of about forty percent of students, there is average difference between scientific and common English language. The other group of respondents placed in "very high category" is 18 out of $120(15 \%)$. According to them, there is a great difference between scientific and common English language. The last category of respondents is placed in "not at all" category, which is 12 out $120(10 \%)$. They do not see any difference between scientific and common English language.

\section{The First Time Understanding Level of Reading Textbooks}

Table 7. The First Time Understanding Level of Reading Textbooks

\begin{tabular}{cccccc}
\hline & Very high & High & Medium & Not at all & Total \\
\hline $\begin{array}{c}\text { The first time } \\
\text { understanding } \\
\text { level of } \\
\begin{array}{c}\text { reading } \\
\text { textbooks }\end{array}\end{array}$ & $08(6.66 \%)$ & $37(30.83 \%)$ & $68(56.66 \%)$ & $07(5.83 \%)$ & 120 \\
\end{tabular}

The current research study also investigated the views and attitudes of students about the question, "At reading first time, up to what extent you have understood your textbooks?" The responses are analyzed on the basis of four categories i.e. very high, high, medium and not at all. The table demonstrates that majority of the respondents are in "medium category" i.e. 68 out of $120(56.66 \%)$. About seventy percent of students have understood their textbooks up to some extent in their first reading. They also said that they would need more than one reading of the text for understanding and conceptual clarity. The next group of respondents is placed in "high category" i.e. 37 out of $120(30.83 \%)$. In the view of about thirty percent of students, they would understand the larger part except for some very difficult passages during their first reading. The other group of 
respondents is placed in "very high category" i.e. 8 out of $120(6.66 \%)$. These students have not understood the text at first reading. They are faced extreme difficulties in it. The last category of respondents is placed in "not at all" category, which is 07 out 120 (5.83\%). In every class there are certain students, which are hard-working and considered intelligent students. These students have selfcapabilities of learning and motivation. The semester system and university education had also polished their skills. They would understand and comprehend the text without difficulties.

\section{The Identification of Reading Habits}

Table 8. The Identification of Reading Habits

\begin{tabular}{|c|c|c|c|c|c|}
\hline & & Yes & No & Partially & Total \\
\hline 1. & $\begin{array}{l}\text { I can study the context } \\
\text { for the meaning of a } \\
\text { word, I don't know }\end{array}$ & $\begin{array}{c}101 \\
(84.16 \%)\end{array}$ & $19(15.83 \%)$ & $0(0 \%)$ & 120 \\
\hline 2. & $\begin{array}{l}\text { In reading process, I } \\
\text { use my knowledge for } \\
\text { interpretation }\end{array}$ & $94(78.33 \%)$ & $26(21.66 \%)$ & $0(0 \%)$ & 120 \\
\hline 3. & $\begin{array}{l}\text { I can find the books of } \\
\text { my taste and } \\
\text { curriculum in library }\end{array}$ & $82(68.33 \%)$ & $38(31.66 \%)$ & $0(0 \%)$ & 120 \\
\hline 4. & $\begin{array}{l}\text { During the reading I } \\
\text { search for different } \\
\text { words, which has the } \\
\text { same meaning }\end{array}$ & $65(54.16 \%)$ & $55(45.83 \%)$ & $0(0 \%)$ & 120 \\
\hline 5. & I like to read for fun & $26(21.66 \%)$ & $94(78.33 \%)$ & $0(0 \%)$ & 120 \\
\hline 6. & $\begin{array}{l}\text { I always share the } \\
\text { titles of good books } \\
\text { with my friends }\end{array}$ & $45(37.5 \%)$ & $75(62.5 \%)$ & $0(0 \%)$ & 120 \\
\hline 7. & $\begin{array}{l}\text { I have some favorite } \\
\text { authors and usually } \\
\text { would read several } \\
\text { books by these writers }\end{array}$ & $25(20.83 \%)$ & $95(79.16 \%)$ & $0(0 \%)$ & 120 \\
\hline
\end{tabular}

In the above table the field data regarding "the identification of reading habits of students" contains different statements about the reading habits of students. These are analyzed on the basis of two categories i.e. yes and no. In the first statement, "I can study the context for the meaning of a word, I don't know", majority of the respondents which is 101 out of $120(84.16 \%)$, agree and reply in "Yes". This figure shows that above eighty percent students have done contextual studies. They study the meaning of different words and also consult dictionary as well as context. The next twenty percent students do not agree with the statement. Hence, these students could not rely upon context for meanings of different words. Secondly, "In reading process, I use my knowledge for interpretation", majority of the respondents, which is 94 out of 120 (78.33\%), agree with the statement. This figure shows that up to eighty percent students have used their background knowledge of English language to clear the contextual meaning of the text.

The next twenty percent students do not agree with the statement. Hence, these students could not use their background knowledge of English language to clear the contextual meaning of the text.Thirdly, the reply to "I can find the books 
of my taste and curriculum in library" of majority of the respondents, which is 82 out of $120(68.33 \%)$ is positive. This figure shows that up to seventy percent students have found books of their taste and curriculum in library. They tend to enjoy their studies a lot because they have the skill to utilize curricular material and valuable books.

The next twenty percent students do not agree the statement. Hence, these students could not find books of their taste and curriculum in library. These type of problems also affected the studies of the students. Fourthly, reply to "During the reading I search for different words, which has the same meaning" of the majority i.e. 65 out of $120(54.16 \%)$, is positive. This figure shows that above fifty percent students have studied different forms of the same word and this kind of practice can improve their vocabulary and enhance their reading ability. The other forty five percent students do not agree with the statement. Hence, these students could not study different forms of the same word. They are not interested in their vocabulary building and the related language skills.

The statement relating to "I like to read for fun" was positively responded to by the majority i.e. 65 out of $120(54.16 \%)$. This figure shows that these students have enjoyed their course and studies. These are the students with extraordinary skills and abilities because they consider that reading \& studies are fun. Up to forty five percent students do not agree with the statement. Hence, these students are not interested in their field of study. They consider reading and learning an extra activity. Sixthly, the statement "I always share the titles of good books with my friends" was "No" to the majority i.e. 75 out of $120(62.5 \%)$. This figure shows that these students just concentrated on their concerned course work and they are not aware about the new inventions and advancements in their fields. Hence, they do not study books other than their curriculum.

The other, below forty five percent students agreed to the statement. Hence, these students are aware about the new inventions and advancements in their fields. They study new and advanced books other than their curriculum and share their knowledge and the titles of good books with their friends.Lastly, the opinion of many students to "I have some favorite authors and usually read several books by these writers" was negative i.e. 95 out of $120(79.16 \%)$. This figure shows that these students have limited knowledge and are restricted the very few authors whose books are part of the curriculum. They are not aware about the new inventions and advancements in their fields. They have no favorite authors and would not study extra books other than their curriculum. The other, below forty five percent students agrees that they are prone to study books of their favorite authors. These are the hard-working and intelligent students of their class. These students are interested in their field and are aware about the new inventions and advancements in their fields.

\section{FINDINGS AND CONCLUSION}

The analysis of data regarding students' previous knowledge about English language reading skill, the statistical analysis reveals that the performance of about sixty percent students in English subject at intermediate level is at average standard. These students have brought with them some basic knowledge about English language especially reading. Their level of achievement was 
therefore up to some extent in English language. They have the potential and basic knowledge to get further improved during university education. Those students whose performance at HSSC level was below average relies on the University for maximizing their knowledge of the skills investigated during the study.

After studying at the university and spending time on the campus, those students who have commendable performance at pre-university level show considerable improvement and their understanding of English has further improved. Those students with less exposure to the language have also improved to varying degrees in their BS classes. This indicates the positive impact of English language subjects included in the curriculum. The research study revealed that some science students do not take English language learning seriously and they spend most of their time in learning the content of their science subjects. The reasons behind this mind set are several. First, the number of taught courses that deal with English language is very less in comparison to other subjects. According to conservative estimates, students are exposed to five subjects in each semester. They study about forty subjects throughout their degree. Out of them, only four specifically focus English language. Second, the science teachers do not seriously notice and question the performance of students at grammatical level that further alienate the students from the need of learning the language. Thirdly, the English language subjects are given less importance at institutional level and students are asked to perform better in the major courses while English language is mistakenly classed with minor or other courses.

The investigation showed that the performance of students improved with each passing semester and the number of good performances in the reading skills increased as they advanced in the semester. In other words, the level of understanding of English was better in students of advanced semesters in comparison to those in the earlier stages of their degrees. This improvement can be understood at two levels. First, the English language classes taken by students in different semesters and the nature of other textbooks that is in English language except Islamic Studies. Second, majority of the teachers use English as the medium of instruction with little or no reference to the mother tongue. These measures have far reaching impact on setting trends and motivating students to improve in the language.

As far as reading is concerned, many students know about skimming, scanning and other related techniques of good reading. It is however observed that formal exposure to the techniques is not up to the desired level. In other words, the teachers do not take great pain in allowing students to know and to master their reading skill. The research study further indicated that the students needed focused sessions and training programmes to know about the art of reading.

Encouraging factors leading science students to develop reading skills in English can be:

1. Science students need to develop their reading skills in English because they study books, articles, etc., through it.

2. They want to maintain smooth life in social sphere of life.

3. To enter government, semi-government or private sectors pursuing jobs. 
4. To pass tests like GAT, IELTS, NTS etc. because it have reading proficiency questions.

5. To pursue higher study abroad.

\section{REFERENCES}

Aydogan, H., and Akbarov, A. A. (2014). The four basic language skills, whole language \& integrated skill approach in mainstream university classrooms in turkey. Mediterranean Journal of Social Sciences, 5(9), 672-680.

Holden, J. (2004). Creative reading. London: Demos.

Khalid, S. M., and Khan, M. F. (2006.) Pakistan: the state of education. The Muslim World, 96(2), 305-322.

Nunan, D. (2001). Second language acquisition. Carter, R. \&Nunan, D., (eds.). The Cambridge guide to teaching english to speakers of other languages. Cambridge: Cambridge University Press.

Roberts, M .S., and Wilson, J. D. (2006). Reading attitudes and instructional methodology: How might achievement become affected? Reading Improvement, 43(2), 64-69.

Tran, A. T. (2006). An approach to basic-vocabulary development for English language learners. Reading Improvement, 43(3), 157-162. 